OPEN ACCESS

Edited by:

Vincent Pialoux

Claude Bernard University Lyon 1 .

France

Reviewed by:

Ralph F. Fregosi,

University of Arizona, USA

Aaron Petersen,

Victoria University, Australia

*Correspondence:

Eduardo Salazar-Martínez eduardosm1989@gmail.com

Specialty section:

This article was submitted to

Exercise Physiology,

a section of the journal

Frontiers in Physiology

Received: 22 November 2016

Accepted: 22 February 2017

Published: 08 March 2017

Citation:

Salazar-Martínez E, Gatterer H,

Burtscher M, Naranjo Orellana J and Santalla A (2017) Influence of Inspiratory Muscle Training on

Ventilatory Efficiency and Cycling Performance in Normoxia and

Hypoxia. Front. Physiol. 8:133.

doi: 10.3389/fphys.2017.00133

\section{Influence of Inspiratory Muscle Training on Ventilatory Efficiency and Cycling Performance in Normoxia and Hypoxia}

\author{
Eduardo Salazar-Martínez ${ }^{1 *}$, Hannes Gatterer ${ }^{2}$, Martin Burtscher ${ }^{2}$, José Naranjo Orellana ${ }^{1}$ \\ and Alfredo Santalla ${ }^{1}$
}

${ }^{1}$ Department of Sports and Computing, Pablo de Olavide University, Seville, Spain, ${ }^{2}$ Department of Sport Science, Medical Section, University of Innsbruck, Innsbruck, Austria

The aim of this study was to analyse the influence of inspiratory muscle training (IMT) on ventilatory efficiency, in normoxia and hypoxia, and to investigate the relationship between ventilatory efficiency and cycling performance. Sixteen sport students (23.05 \pm 4.7 years; $175.11 \pm 7.1 \mathrm{~cm} ; 67.0 \pm 19.4 \mathrm{~kg} ; 46.4 \pm 8.7 \mathrm{ml} \cdot \mathrm{kg}^{-1} \cdot \mathrm{min}^{-1}$ ) were randomly assigned to an inspiratory muscle training group (IMTG) and a control group (CG). The IMTG performed two training sessions/day [30 inspiratory breaths, 50\% peak inspiratory pressure (Pimax), 5 days/week, 6-weeks]. Before and after the training period subjects carried out an incremental exercise test to exhaustion with gas analysis, lung function testing, and a cycling time trial test in hypoxia and normoxia. Simulated hypoxia $\left(\mathrm{FiO}_{2}=16.45 \%\right)$, significantly altered the ventilatory efficiency response in all subjects $(p<0.05)$. Pimax increased significantly in the IMTG whereas no changes occurred in the $C G$ (time $\times$ group, $p<0.05$ ). Within group analyses showed that the IMTG improved ventilatory efficiency $\left(\mathrm{VE}_{\mathrm{E}} \mathrm{NCO}_{2}\right.$ slope; $\left.\mathrm{EqCO}_{2} \mathrm{VT}_{2}\right)$ in hypoxia $(p<0.05)$ and cycling time trial performance $\left[\mathrm{W}_{T \max }(\mathrm{W}) ; \mathrm{W}_{T \text { Tmean }}(\mathrm{W}) ; \mathrm{PTF}(\mathrm{W})\right](p<0.05)$ in hypoxia and normoxia. Significant correlations were not found in hypoxia nor normoxia found between ventilatory efficiency parameters $\left(\mathrm{V}_{\mathrm{E}} \mathrm{NCO}_{2}\right.$ slope; $\left.\mathrm{LEqCO}_{2} ; \mathrm{EqCO}_{2} \mathrm{VT}_{2}\right)$ and time trial performance. On the contrary the oxygen uptake efficiency slope (OUES) was highly correlated with cycling time trial performance $(r=0.89 ; r=0.82 ; p<0.001)$ under both conditions. Even though no interaction effect was found, the within group analysis may suggest that IMT reduces the negative effects of hypoxia on ventilatory efficiency. In addition, the data suggest that OUES plays an important role in submaximal cycling performance.

Keywords: $\mathrm{V}_{\mathrm{E}} / \mathrm{VCO}_{2}$ slope, cycling performance, ventilation, chemosensitivity, time trial

\section{INTRODUCTION}

Ventilatory efficiency can be defined as the relationship between carbon dioxide production $\left(\mathrm{VCO}_{2}\right)$ and ventilation $\left(V_{\mathrm{E}}\right)$. Increased $V_{\mathrm{E}}$ and the removal of $\mathrm{CO}_{2}$ during physical exercise are essential for homeostatic control of whole body pH (Brown et al., 2013). There are four common ways for measuring ventilatory efficiency during an incremental test: (a) using the slope of the relationship between $\mathrm{VCO}_{2}$ and $V_{\mathrm{E}}\left(V_{\mathrm{E}} / \mathrm{VCO}_{2}\right.$ slope; Ingle et al., 2007), (b) the lowest equivalent of 
$\mathrm{CO}_{2}$ during the incremental test $\left(\mathrm{LEqCO}_{2}\right.$; Sun et al., 2002), (c) the equivalent of $\mathrm{CO}_{2}$ at the second ventilatory threshold $\left(\mathrm{EqCO}_{2} \mathrm{VT}_{2}\right.$; Sun et al., 2002), and (d) the oxygen uptake efficiency slope (OUES; Baba et al., 1999a). Generally, a lower equivalent of $\mathrm{CO}_{2}$ indicates a greater ventilatory efficiency (Sun et al., 2002). The OUES represents the rate of increase of $\mathrm{VO}_{2}$ in response to a given $V_{\mathrm{E}}$ during incremental exercise, indicating how effectively oxygen is extracted and taken into the body (Baba et al., 1996).

In the clinic field ventilatory efficiency has been widely used as a prognostic marker to determine exercise limitation (Ingle et al., 2007; Arena et al., 2008; Laveneziana et al., 2010). Indeed, a relationship has been reported between sudden dead risk in hypertrophic cardiomyopathy and ventilatory efficiency (Magrì et al., 2016). However, the importance of the ventilatory efficiency for sport performance remains unclear. On one hand, Brown et al. (2013) did not find a relationship between maximum oxygen uptake $\left(\mathrm{VO}_{2 \max }\right)$ and OUES in juvenile cyclists. In the same way, we did not find a relationship between $\mathrm{VO}_{2 \max }$, peak power output (PPO), and $V_{\mathrm{E}} / \mathrm{VCO}_{2}$ slope in world-class cyclists (Salazar-Martínez et al., 2016). On the other hand, a significant correlation was found between OUES and $\mathrm{VO}_{2 \max }$ in young active women (Mourot et al., 2004).

In hypoxia, the reduced partial pressure of oxygen $\left(\mathrm{PO}_{2}\right)$ and the resulting arterial desaturation stimulates $V_{\mathrm{E}}$ (Babcock et al., 1995). Although the increased $V_{E}$ during exercise in hypoxia $\left(\mathrm{FIO}_{2}=0.15\right)$ increases $\mathrm{PaO}_{2}$ (Warner and Mitchell, 1990) it also leads to a higher oxygen cost of breathing compared to normoxia (Babcock et al., 1995). Additionally, in hypoxia, $V_{\mathrm{E}}$ may increase in excess of what would be required to maintain partial pressure levels of carbon dioxide $\left(\mathrm{PaCO}_{2}\right.$; Warner and Mitchell, 1990). Therefore, a certain ventilatory inefficiency could be expected in hypoxia due to this overshoot in $V_{\mathrm{E}}$. However, high ventilatory efficiency is essential to maintain adequate level of $\mathrm{PaO}_{2}$ and $\mathrm{PaCO}_{2}$ with a lower breathing work in high altitude (Bernardi et al., 2006). In this regard, it may be assumed that efficient breathing may play an important role in the regulation of $\mathrm{PaO}_{2}$ and $\mathrm{PaCO}_{2}$ and achieving a higher sport performance in hypoxia.

In accordance, inspiratory muscle training (IMT) has been shown to be an effective method to improve both the ventilatory response in normoxia and hypoxia (Downey et al., 2007; Esposito et al., 2010) and the alveolar-arterial gradient in hypoxia (Esposito et al., 2010). Thus, it could be speculated that welltrained inspiratory muscles may help to preserve $\mathrm{PaO}_{2}$ in hypoxia due to improved ventilation-perfusion matching and to prevent excessive $\mathrm{CO}_{2}$ output due to less hyperventilation. However, to the best of our knowledge, whether or not IMT may improve the ventilatory efficiency under hypoxia conditions has not yet been tested.

Next to the effect on ventilation, IMT has been shown to improve sport performance as well (Romer et al., 2002a; Wells et al., 2005). However, the mechanisms responsible for the performance improvements after IMT remain controversial (Edwards and Walker, 2009). The mechanisms suggested to improve performance include a hypertrophy of diaphragm (Downey et al., 2007), an increase in blood flow to the locomotor muscles (Harms et al., 1997) and a reduction in subjective perception of fatigue and dyspnea ratings (Downey et al., 2007). Additionally, Sheel (2002) hypothesized that changes in performance after IMT could be related to improvements on ventilatory efficiency. However, to the best of our knowledge there are no studies evaluating the relationship between changes in sport performance after IMT and ventilatory efficiency. After IMT, the metabolic demand of the inspiratory muscles during exercise are reduced (Babcock et al., 1995), thus contributing to a lower overall $\mathrm{O}_{2}$ uptake and $\mathrm{CO}_{2}$ output. In situations where the ventilatory efficiency is impaired, for example in hypoxia, such effects may influence exercise performance (Roussos, 1985).

Therefore, the aim of this study was (a) to evaluate the influence of IMT on ventilatory efficiency in normoxia and hypoxia, and (b) to investigate the relationship between ventilatory efficiency and cycling performance under both conditions.

We hypothesized that IMT improves ventilatory efficiency in normoxia and especially in hypoxia and reduces the metabolic demands of the respiratory muscles in both conditions. We also hypothesized that improvements in submaximal cycling performance can be linked to improvements in ventilatory efficiency in normoxia and hypoxia.

\section{MATERIALS AND METHODS}

\section{Subjects}

Sixteen physically active and healthy participants $[n=9$ male $(23.44 \pm 2.7$ years; $180.22 \pm 3.5 \mathrm{~cm} ; 78.2 \pm 5.5$ $\left.\mathrm{kg} ; 48.39 \pm 7.28 \mathrm{ml} \cdot \mathrm{kg}^{-1} \cdot \mathrm{min}^{-1}\right) ; n=7$ female $(25.37$ \pm 3.24 years; $168.75 \pm 5.1 \mathrm{~cm} ; 62.62 .2 \pm 9.47 \mathrm{~kg} ; 38.15$ $\left.\pm 6.57 \mathrm{ml} \cdot \mathrm{kg}^{-1} \cdot \mathrm{min}^{-1}\right)$ ] were selected for the study. Each participant completed a health questionnaire before being included in the study. Participants with health diseases, breathing problems, or obstructive defects were excluded from the study. Before starting the study, written informed consent was obtained from each participant in accordance with the Declaration of Helsinki. The study was approved by the Ethics Committee of the University of Innsbruck.

\section{Design}

Participants were randomly assigned to either an inspiratory muscle training group (IMTG) or a control group (CG). The IMTG performed two training sessions per day, 5 days per week during a period of 6-weeks. Each participant completed 30 inspiratory breaths with a PowerBreath device (PowerBreathe ${ }^{\circledR}$, K3) at $50 \%$ of their individual Pimax. Inspiratory training load was adjusted weekly at $50 \%$ of the individual Pimax. Every training session was performed under expert supervision. The CG did not carry out any inspiratory training during the experimental period. This procedure seems to be adequate as a placebo effect is not expected. For instance, when considering differences between trials that included a control group and studies that did not, $69 \%$ of the placebo-controlled studies showed a positive outcome for RMT (i.e., performance improvements for the RMT groups significantly exceeded those for the control groups), which is very similar to the $75 \%$ positive outcomes of the studies without any controls (Illi et al., 2012). 
Participants were advised not to change normal physical training habits during the experimental period.

\section{Pulmonary Function Tests}

Before and after the experimental period, participants performed lung function testing (Schiller SP- $1^{\circledR}$, Switzerland) to assess the forced vital capacity (FVC), forced expiratory volume during the first second $\left(\mathrm{FEV}_{1}\right)$, the ratio between forced expiratory capacity during the first second and vital capacity $\left(\mathrm{FEV}_{1} / \mathrm{VC}\right)$, the peak expiratory flow $(\mathrm{PEF})$, and the peak inspiratory flow (PIF; Table 1). The best attempt out of three tests was included in the analysis. Peak inspiratory mouth pressure (Pimax) was determined with a portable device (PowerBreathe ${ }^{\circledR}$, K3). During the Pimax test participants had to inspire as fast as possible from a normal expiration. Each participant repeated the test until the measurements were stable. Pimax was measured weekly using the same testing protocol.

\section{Incremental Exercise Testing}

Before (Pre) and after (Post) the training period participants performed maximum incremental exercise tests in normoxia and hypoxia (overall four tests). Each test was separated by $48 \mathrm{~h}$. During the tests, oxygen uptake $\left(\mathrm{VO}_{2}\right)$, carbon dioxide output $\left(\mathrm{VCO}_{2}\right)$, respiratory exchange ratio (RER), ventilation $\left(V_{\mathrm{E}}\right)$, breathing frequency $(\mathrm{BF})$, tidal volume $(\mathrm{VT})$, oxygen equivalent $\left(\mathrm{EqVO}_{2}\right)$, and carbon dioxide equivalent $\left(\mathrm{EqCO}_{2}\right)$ were measured breath by breath with a portable gas analyser (Jaeger Oxygen ${ }^{\mathrm{TM}}{ }^{\circledR}$, Germany). The system was calibrated prior to each test with gas mixtures of known concentration. Tests were carried out on a cycle ergometer (RBM Cyclus $2^{\circledR}$, Germany). After $4 \mathrm{~min}$ of warming up, participants started the test at $50 \mathrm{~W}$ and then the load was increased by $25 \mathrm{~W}$ each minute until volitional exhaustion. Achievement of maximum oxygen uptake $\left(\mathrm{VO}_{2 \max }\right)$ was accepted when a plateau was found in the relationship between $\mathrm{VO}_{2}$ and power output or when three of the four criteria for maximal $\mathrm{VO}_{2 \max }$ were obtained (Howley et al., 1995). Tests were carried out at

TABLE 1 | Results of pulmonary function testing pre and post experimental period (Mean $\pm S D$ ).

\begin{tabular}{|c|c|c|c|c|}
\hline & \multicolumn{2}{|c|}{ IMTG } & \multicolumn{2}{|c|}{ CG } \\
\hline & Pre & Post & Pre & Post \\
\hline FVC (I) & $5.44 \pm 1.14$ & $4.67 \pm 1.38$ & $5.06 \pm 1.17$ & $4.96 \pm 0.93$ \\
\hline $\mathrm{FEV}_{1}(\mathrm{I})$ & $4.64 \pm 0.92$ & $4.19 \pm 0.8$ & $4.31 \pm 0.85$ & $4.06 \pm 0.79$ \\
\hline $\mathrm{FEV}_{1} / \mathrm{NC}(\%)$ & $84.13 \pm 11.58$ & $82.51 \pm 9.19$ & $82.33 \pm 6.28$ & $79.84 \pm 6.48$ \\
\hline $\operatorname{PEF}\left(I \cdot \mathrm{s}^{-1}\right)$ & $9.27 \pm 2.23$ & $8.2 \pm 1.53$ & $8.9 \pm 2.47$ & $8.73 \pm 2.4$ \\
\hline $\operatorname{PIF}\left(I \cdot S^{-1}\right)$ & $7.04 \pm 1.92$ & $8.31 \pm 2.39$ & $7.12 \pm 1.2$ & $7.57 \pm 2.2$ \\
\hline $\begin{array}{l}\text { Pimax } \\
\left(\mathrm{cm} \mathrm{H}_{2} \mathrm{O}\right)\end{array}$ & $119.6 \pm 37.36$ & $166.91 \pm 42.65^{\star}$ & $130.55 \pm 33.58$ & $146.72 \pm 40.62$ \\
\hline
\end{tabular}

FVC, forced vital capacity; FEV1, forced expiratory volume during the first second; FEV1NC, ratio between forced expiratory volume during the first second and vital capacity; PEF, peak expiratory flow; PIF, peak inspiratory flow; Pimax, peak inspiratory pressure.

${ }^{*} p<0.05$ post vs. pre training. approximately the same time of the day in an air-conditioned normobaric hypoxic chamber (size $4.75 \times 2.25 \mathrm{~m}$, LowOxygen ${ }^{\circledR}$, Germany). During the normoxia testing the hypoxic chamber was switched off whereas during the hypoxia setting the chamber was set at a simulated altitude of $2,500 \mathrm{~m}\left(\mathrm{FiO}_{2}=16.45 \%\right)$. Participants were blinded to the simulated altitude of the hypoxic chamber. Participants were advised to avoid exhausting exercise 1 day before the tests and to take any ergogenic aids (e.g., caffeine).

\section{Time Trial Performance}

Ninety minutes after the incremental test, cycling endurance performance was evaluated by a $10 \mathrm{~min}$ time trial (TT). The cycle ergometer was shifted to a fixed pedal force in which power output was dependent on the pedaling rate. Pedal force for each participant was set in order that pedaling at $90 \mathrm{rpm}$ produced $85 \%$ (rounded to $5 \mathrm{~W}$ ) of peak power output determined by the incremental cycle ergometer test. During the test, cyclists were strongly encouraged to choose a maximal pedaling rate that could be maintained for the respective test duration. As with the incremental test, each participant performed the $\mathrm{TT}$, under normoxic $\left(\mathrm{TT}_{\text {nor }}\right)$ and under hypoxic conditions $\left(\mathrm{TT}_{\text {hyp }}\right)$ separated by $48 \mathrm{~h}$, before and after the experimental period. During each TT-test peak power output $\left(\mathrm{W}_{\max }\right)$, mean power output $\left(\mathrm{W}_{\text {mean }}\right)$, and pedal torque force $(\mathrm{PTF})$ were recorded.

\section{Test-Retest Reproducibly of Time Trial Test}

The coefficient of variation for the time trial test in the control group in normoxia was $14.9 \%$ in the pre-test and $15.9 \%$ in the post-test (Figure 1A). In hypoxia, the coefficient of variation for the time trial test in the control group was $17.9 \%$ in the pre-test and $17.8 \%$ in the post-test (Figure 1B). The intra-class correlation coefficient for the time trial test in the control group was 0.92 in normoxia and 0.93 in hypoxia.

\section{Ventilatory Efficiency}

The $V_{\mathrm{E}} / \mathrm{VCO}_{2}$ slope was calculated from the slope of the relationship between $\mathrm{VCO}_{2}$ and $V_{\mathrm{E}}$ during each incremental exercise test. To exclude the influence of the respiratory compensation due to acidosis during highly intensive exercise, the $V_{\mathrm{E}} / \mathrm{VCO}_{2}$ slope was determined from the beginning of the test until the second ventilatory threshold $\left(\mathrm{VT}_{2}\right) \cdot \mathrm{VT}_{2}$ was identified by an increase in the ventilatory equivalent of $\mathrm{CO}_{2}$ $\left(\mathrm{EqCO}_{2}\right)$ and a decrease in end tidal partial pressure of carbon dioxide $\left(\mathrm{PETCO}_{2}\right.$; Lucía et al., 2000). Oxygen uptake efficiency slope (OUES) was calculated from the linear relationship of $\mathrm{VO}_{2}$ vs. the logarithm of $V_{\mathrm{E}}$ during exercise $\left(\mathrm{VO}_{2}=\mathrm{a} \log _{10} V_{\mathrm{E}}+\mathrm{b}\right)$.

\section{Statistics Analysis}

Data are expressed as mean $\pm S D$ for each variable. The statistical power for the chosen sample size of 16 participants ( 9 in the IMTG and 7 in the CG) was $>90 \%$; alpha $=0.05$. The power calculation ( $G^{*}$ Power 3.1.7) was based on expected changes in Pimax and TT performance ( $\mathrm{W}_{\text {TTmean }}$ ) due to IMT (Romer et al., 2002a). The normal distribution of the data was checked by the 

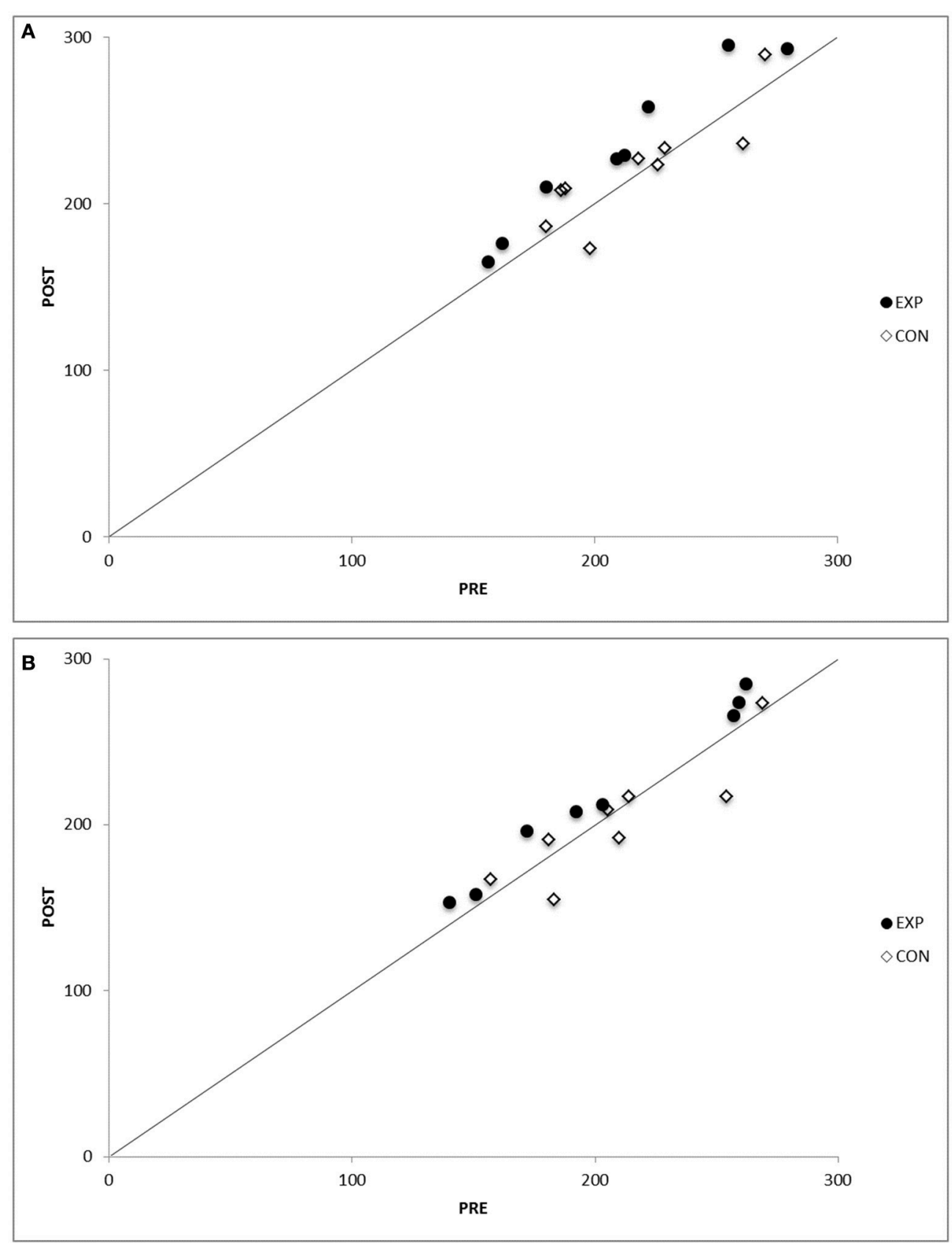

FIGURE 1 | (A) Test-retest reproducibility in the control/experimental group subjects during the time trial test (TT) test, before (Pre), and after (Post) the intervention period in normoxia. Identity lines are drawn in both graphs. See text for numerical analysis. (B) Test-retest reproducibility in the control/experimental group subjects during the time trial test (TT) test, before (Pre), and after (Post) the intervention period in hypoxia. Identity lines are drawn in both graphs. See text for numerical analysis.

Shapiro-Wilk test. The homogeneity of variance was evaluated by Levene's test. To compare the values obtained for each variable during the test, mixed-effects ANOVA test was used (group $\times$ time $\times$ condition). When significant differences were found, the Bonferroni test was used as a post-hoc test. ANOVA test was also applied to evaluate a possible gender effect (group $\times$ time $\times$ condition $\times$ gender). Effect size $(E S)$ was calculated when a significant difference was found. A correlation analysis
(Pearson-coefficient) was carried out between TT performance variables, incremental test variables and ventilatory efficiency variables with data from both groups and from both test in two different situations (normoxia and hypoxia; Table 6). Linear regression analysis was performed between Pimax, $V_{\mathrm{E}} / \mathrm{VCO}_{2}$ slope and OUES (dependent variables) and TT performance (independent variable) with data from both groups (IMTG and $\mathrm{CG}$ ) and from both tests (Pre and Post) in normoxia. The 
level of significance was set at $p<0.05$ for each statistical analysis.

\section{RESULTS}

No gender effect was identified with regard to the parameters of interest $\left(V_{\mathrm{E}} / \mathrm{VCO}_{2}\right.$ slope, $\mathrm{LEqCO}_{2}, \mathrm{EqCO}_{2} \mathrm{VT}_{2}$, OUES). Baseline values did not differ between groups $\left(V_{\mathrm{E}} / \mathrm{VCO}_{2}\right.$ slope, $\mathrm{LEqCO}_{2}$, $\mathrm{EqCO}_{2} \mathrm{VT}_{2}$, OUES, Pimax, PPO, $\left.\mathrm{TT}_{\mathrm{W} \text { mean }}\right)$. Outcomes of the pulmonary function testing before and after the experimental period are shown in Table 1. Significant differences were found in Pimax between Pre- and Post-test in the IMTG $(p<0.05)$.

\section{Inspiratory Muscle Training (IMT)}

Figure 2 shows the changes in Pimax during the experimental period in both groups. Mean Pimax improved significantly from week- 1 to week-6 in the IMTG $(+28.37 \%, p<0.05)$ with no improvements in the CG (interaction effect, time $\times$ group, $p<0.05)$.

\section{Ventilatory Efficiency}

The group comparison of the ventilatory efficiency variables are shown in Table 3. There were no group differences and no interaction effect in any of the established variables at Pre and Post in normoxia and hypoxia. Significant differences were found between normoxia and hypoxia in the $V_{\mathrm{E}} / \mathrm{VCO}_{2}$ slope, $\mathrm{LEqCO}_{2}$, and $\mathrm{EqCO}_{2} \mathrm{VT}_{2}$ in the Pre-test in both groups $(p<0.05$; Table 2). During the Post-test significant differences between normoxia and hypoxia were found in $\mathrm{LEqCO}_{2}$ and OUES in the IMTG and in $V_{\mathrm{E}} / \mathrm{VCO}_{2}$ slope, $\mathrm{LEqCO}_{2}$ and OUES in the $\mathrm{CG}(p<0.05)$. In both groups significant differences in $V_{\mathrm{E}} / \mathrm{VCO}_{2}$ slope and $\mathrm{EqCO}_{2} \mathrm{VT}_{2}$ were found between Pre and Post in hypoxia $(p<0.05)$.

\section{Time Trial Performance}

Time trial performance parameters are shown in Table 4. During Pre- and Post-test, significant differences between normoxia and hypoxia were found in $\mathrm{W}_{\text {TTmean }(\mathrm{W})}$ and in $\mathrm{W}_{\mathrm{TTmean}}(\mathrm{W} / \mathrm{Kg})$ in both groups $(p<0.05)$. There was no interaction effect in these variables. However, after the experimental period, $\mathrm{W}_{\mathrm{TTmean}}(\mathrm{W})$ and $\mathrm{W}_{\text {TTmean }}(\mathrm{W} / \mathrm{Kg})$ were significantly higher in normoxia and hypoxia in the IMTG $(p<0.05)$. At post, significant differences were found in $\mathrm{W}_{\max }$ between normoxia and hypoxia in both groups $(p<0.05)$. A significant reduction in PTF was found in the CG in hypoxia in both tests (Pre and Post) and in the Post-test in the IMTG $(p<0.05)$. A significant increase in PTF was found in the IMTG in normoxia after IMT $(p<0.05)$.

\section{Incremental Exercise Testing}

$\mathrm{VO}_{2 \max }$ was reduced in hypoxia in both groups compared to normoxia in the Post-test $(p<0.05)$. Compared to normoxia, PPO was reduced in both groups during the Pre- and Posttest in hypoxia $(p<0.05)$. There was no interaction effect. However, PPO increased significantly in the IMTG in normoxia after the experimental period compared to the Pre-test evaluation $(p<0.05)$. Before the experimental period, $V_{\text {Emax }}$ increased

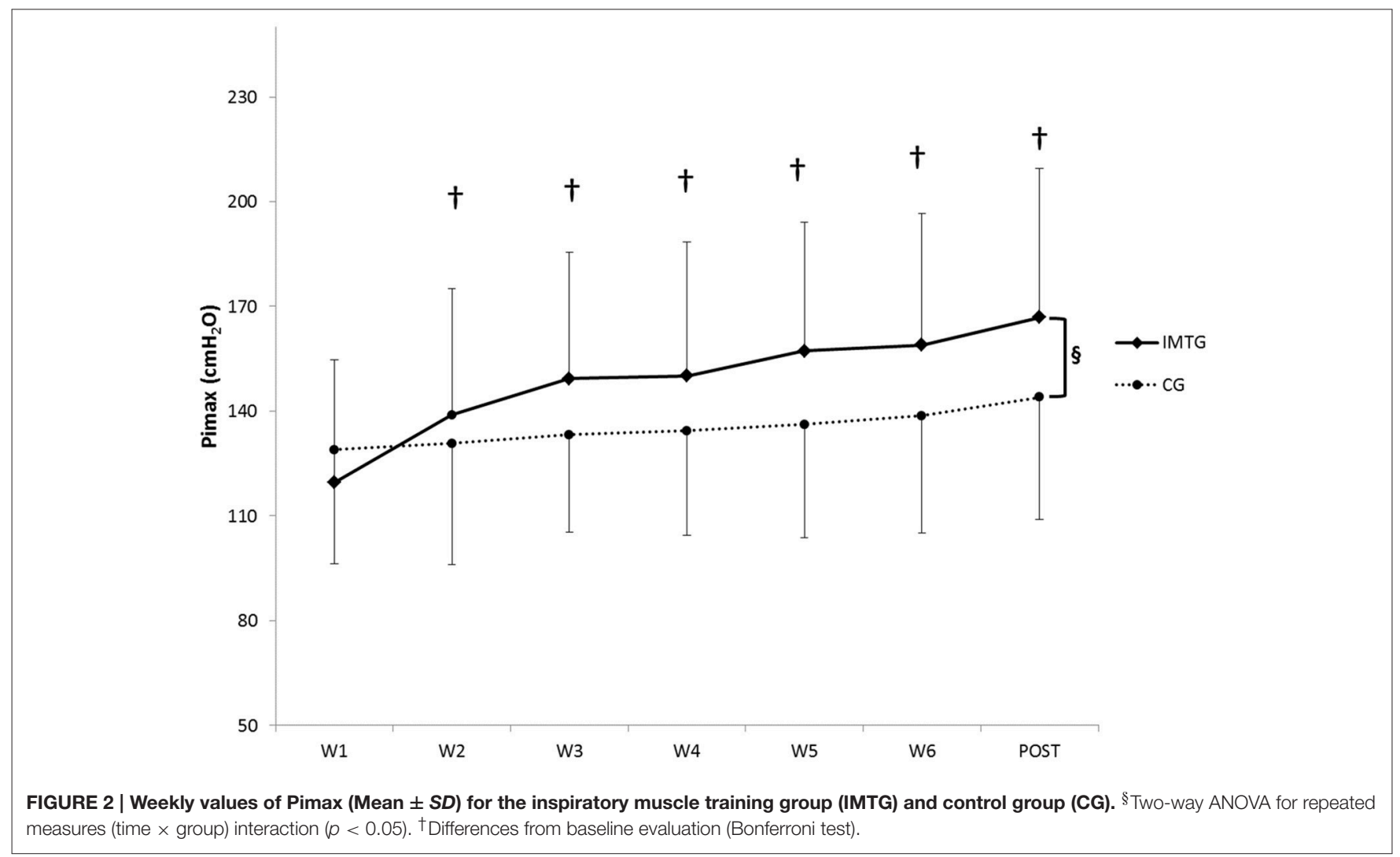


in hypoxic conditions in both groups. After the experimental period, $V_{\text {Emax }}$ increased only in the CG. However, all these variations were not significant in both gorups. $\mathrm{VT}_{\max }$ and $\mathrm{BF}_{\max }$ did not change in any condition.

\section{Correlation and Regression Analysis}

Significant correlations were found between Pimax and $\mathrm{W}_{\mathrm{TTmean}}$, $\mathrm{VO}_{2 \max }, V_{\text {Emax }}$, and PPO with data from both test and both groups in normoxia ( $p<0.05$; Table 6). No correlation was found between ventilatory efficiency variables and performance variables. A significant correlation was found between OUES and maximal performance variables $\left(\mathrm{VO}_{2 \max }, V_{\mathrm{Emax}}, \mathrm{PPO}\right)$ and $\mathrm{W}_{\text {TTmean }}(p<0.05)$ in normoxia and hypoxia (Table 6). A linear relationship was found between muscle breathing strength (Pimax) and TT performance in normoxia $\left(R^{2}=0.69, p=0.00\right.$; Figure 3$)$ and in hypoxia $\left(R^{2}=0.67, p=0.00\right)$. No relationship was found between time trial performance $\left(\mathrm{W}_{\mathrm{TTmean}}\right)$ and ventilatory efficiency $\left(V_{\mathrm{E}} / \mathrm{VCO}_{2}\right.$ slope $)$ in normoxia $\left(R^{2}=\right.$ $0.149, p=0.02$; Figure 4) and in hypoxia $\left(R^{2}=0.02, p=0.81\right)$. $\mathrm{W}_{\text {TTmean }}$ and OUES were significantly related in normoxia $\left(R^{2}=0.647, p=0.00\right.$; Figure 5) and in hypoxia $\left(R^{2}=0.631\right.$, $p=0.01)$.

\section{DISCUSSION}

To the best of our knowledge, this is the first study that investigated the effects of IMT on ventilatory efficiency variables in normoxic and hypoxic conditions. We hypothesized that IMT could improve the ventilatory efficiency response in normoxia and hypoxia. We also hypothesized that improvements in the submaximal cycling performance may be linked to improvements in ventilatory efficiency. The main finding of this study was that IMT improved $V_{\mathrm{E}} / \mathrm{VCO}_{2}$ slope $(-7.95 \%)$ in hypoxia and TT performance in both normoxia $(+10.17 \%)$ and hypoxia $(+6.62 \%)$ conditions. However, despite this withingroup effect no interaction effect was found. Additionally, cycling TT performance was positively related to the OUES in normoxia and hypoxia and to the inspiratory muscle strength (Pimax). These findings partly support (only in OUES) the hypothesis that changes in sport performance after IMT may be linked to changes in ventilatory efficiency.

It is well known that $V_{\mathrm{E}}$ is stimulated in hypoxia mediated by stimulation of the peripheral chemoreceptors (Dempsey and Forster, 1982; Townsend et al., 2002). However, the influence of hypoxic conditions on ventilatory efficiency has not been thoroughly investigated. In the present study, hypoxia at Pre worsened the ventilatory efficiency response in both groups $\left(+18.5 \% V_{\mathrm{E}} / \mathrm{VCO}_{2}\right.$ slope; $+9.58 \% \mathrm{LEqCO}_{2} ;+14.09 \%$ $\mathrm{EqCO}_{2} \mathrm{VT}_{2}$; and $-8.64 \%$ OUES, respectively; Table 2), which is in agreement with the increase in the ventilatory equivalents described at $16 \% \mathrm{FiO}_{2}$ (Ozcelik and Kelestimur, 2004). The increased $V_{\mathrm{E}}$ at altitude, initiated to maintain $\mathrm{SaO}_{2}$ (Rusko et al., 2004; Burtscher et al., 2006; Faiss et al., 2014), may to some extent explain the deterioration of ventilatory efficiency. In addition, in hypoxia $V_{\mathrm{E}}$ may be increased in excess of what would be required to maintain partial pressure levels of carbon dioxide $\left(\mathrm{PaCO}_{2}\right.$; Warner and Mitchell, 1990) thus influencing the relationship between $V_{\mathrm{E}}$ and $\mathrm{VCO}_{2}$.

After the training period, hypoxia did not significantly increase the $V_{\mathrm{E}} / \mathrm{VCO}_{2}$ slope response in the subjects that performed the IMT $[+3.43 \%(\mathrm{ES}=0.4)$ vs. $+9.48 \%$ (ES $=1.3$ ) for the IMTG and CG, respectively]. These changes

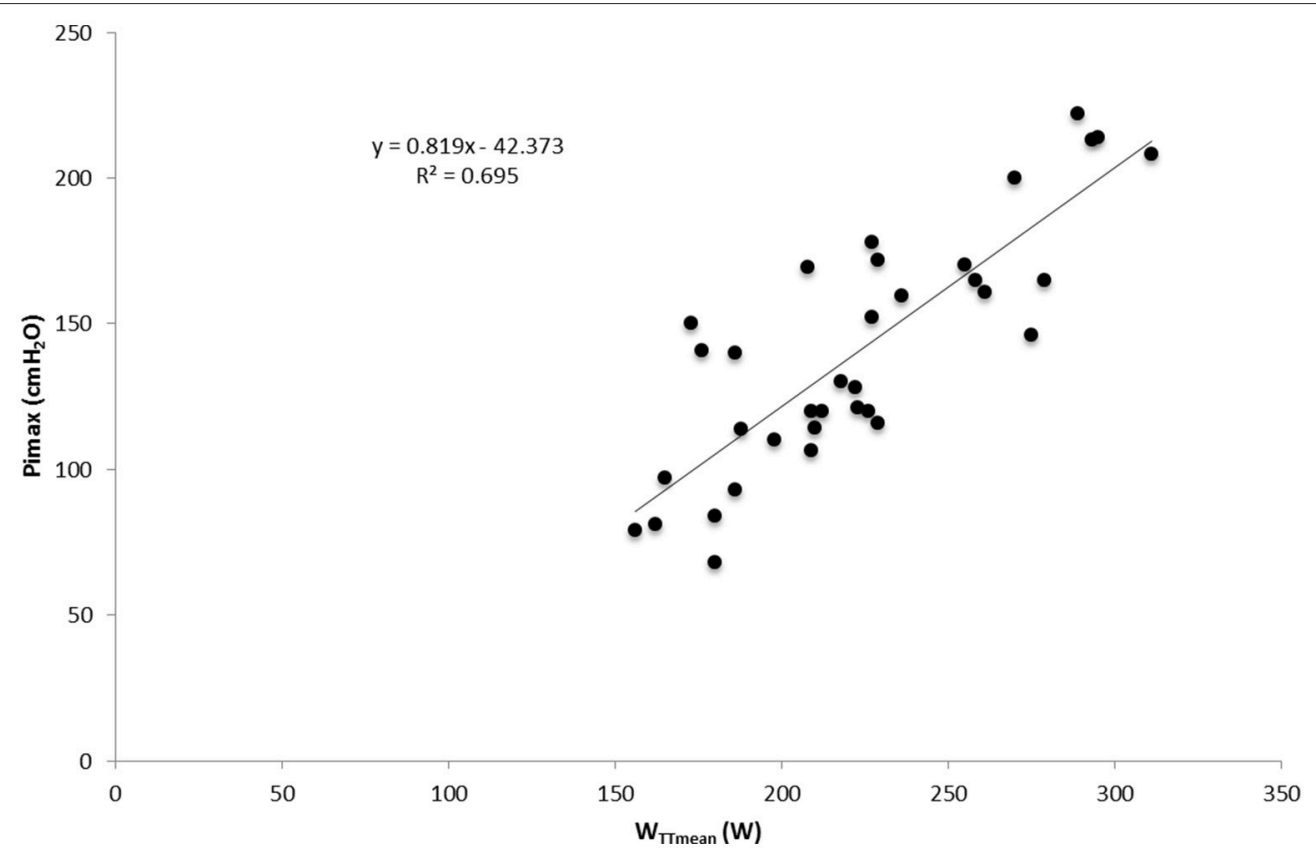

FIGURE 3 | Relationship between inspiratory muscle strength (Pimax) and cycling time trial (TT) performance with data from both groups and both test in normoxia. 


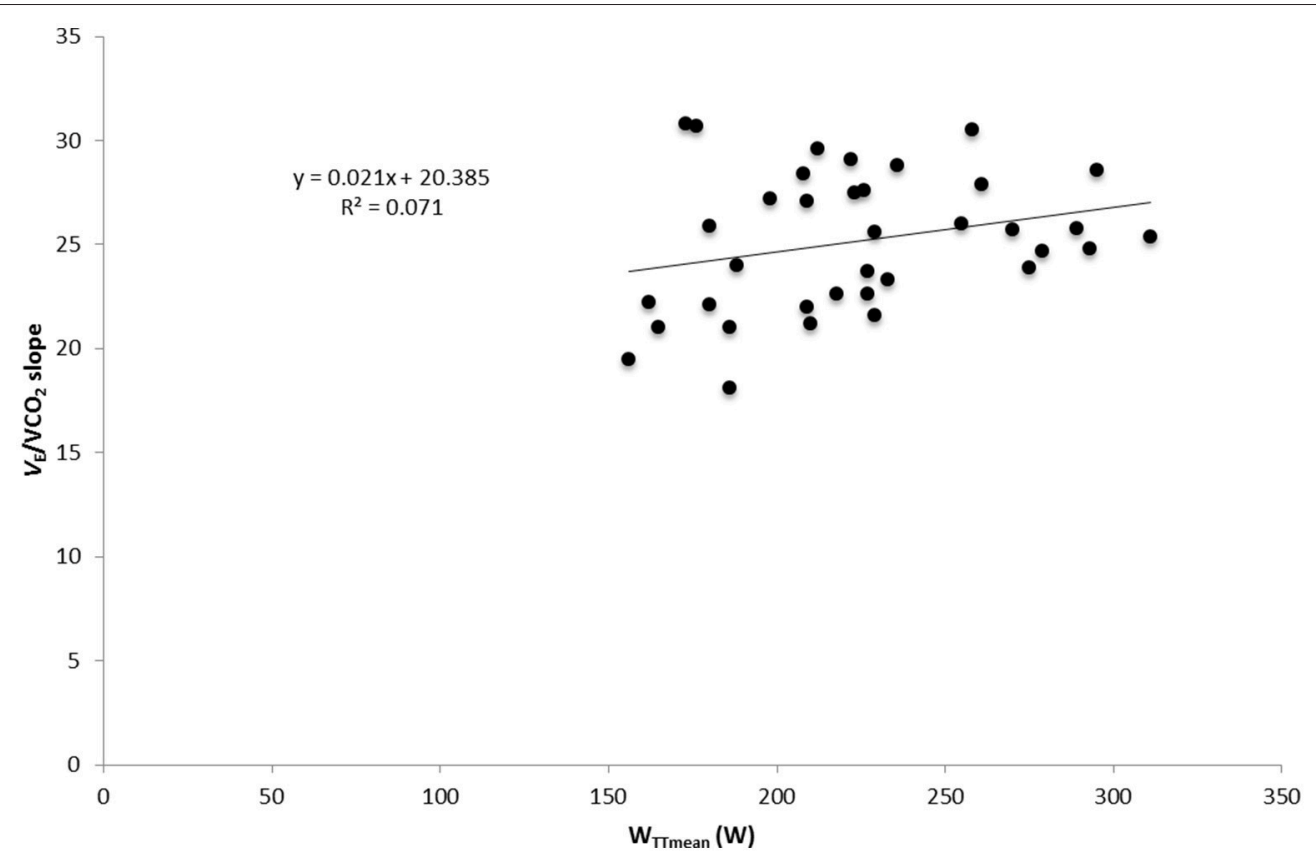

FIGURE 4 | Relationship between cycling time trial (TT) performance and ventilatory efficiency measured as $V_{\mathrm{E}} / \mathrm{VCO}_{2}$ slope with data from both groups and both test in normoxia.

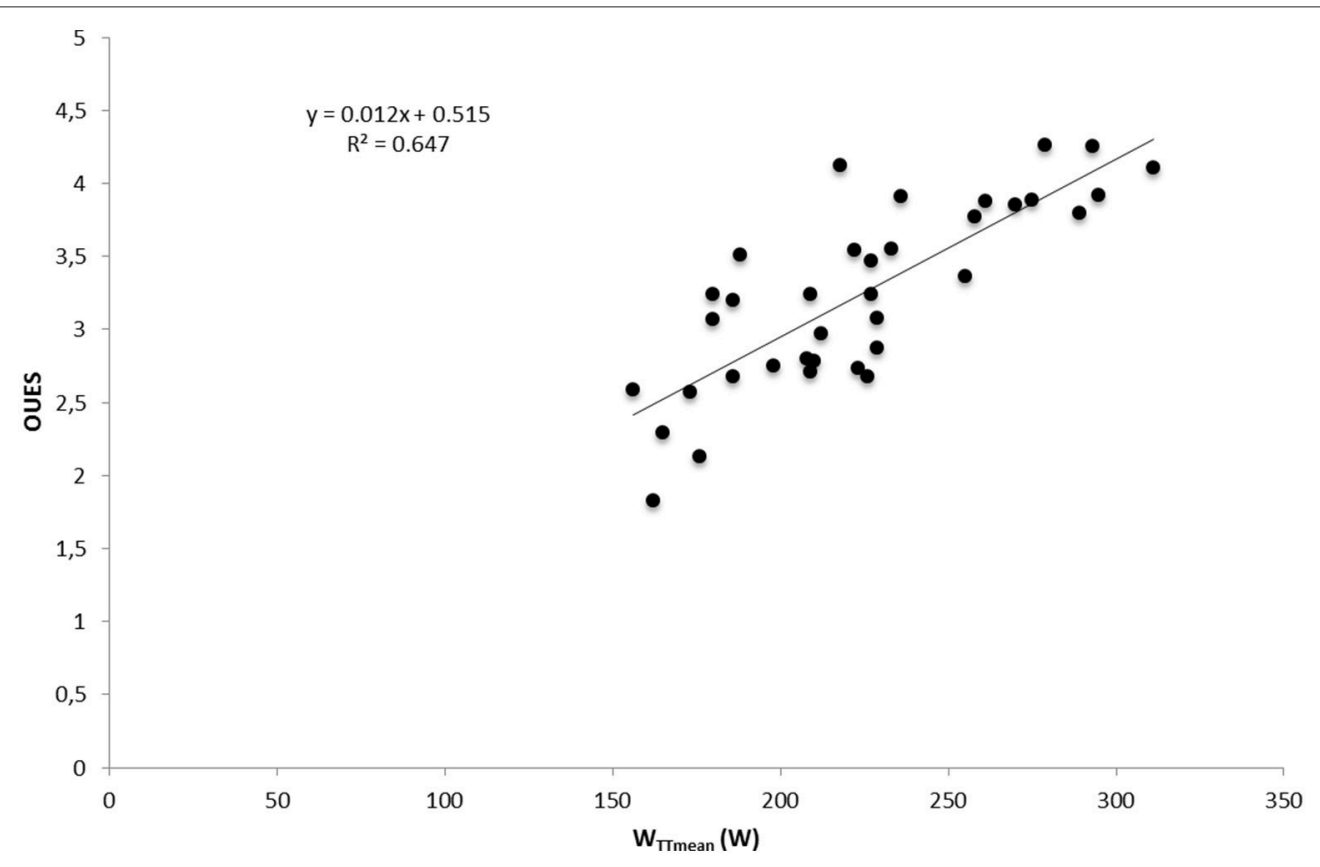

FIGURE 5 | Relationship between cycling time trial (TT) performance and ventilatory efficiency measured as OUES with data from both groups and both test in normoxia.

might be explained by improvements in breathing muscle strength (Pimax) and altered breathing patterns after IMT. Respiratory muscle training has been shown as an effective method to improve A-a gradient and ventilation-perfusion mismatch (Esposito et al., 2010). A better A-a gradient in hypoxia might have reduced the $V_{\mathrm{E}}$ overshoot observed in hypoxia before training (Table 3). In support of this, it has been reported that climbers who managed to climb Mt. Everest and K2 without oxygen, are those with a high ventilatory efficiency and “optimized" breathing patterns (Bernardi et al., 2006). Again, it 
has to be underlined that no interaction effect existed with respect to the altered $V_{\mathrm{E}} / \mathrm{VCO}_{2}$ slope in hypoxia after the training period. Therefore, the reported training effect contains some uncertainty and further studies with a greater sample size are needed to confirm our conclusions.

With regard to cycling performance, TT performance was reduced significantly in both groups before IMT in hypoxia (Table 4). After IMT, only the IMTG improved TT performance in normoxia and hypoxia (Table 4). Our results support previous studies showing a positive effect of IMT on sport performance (Volianitis et al., 2001; Romer et al., 2002a,b; Edwards and Walker, 2009). However, the participants of the present study not only improved their performance in normoxia $(+11.33 \%)$, they also improved their performance in hypoxia $(+7.33 \%)$ despite a reduction in $\mathrm{VO}_{2 \max }(-5.42 \%$; Table 4). It could be hypothesized that IMT reduced the oxygen cost of the breathing muscles allowing higher $\mathrm{O}_{2}$ availability for the locomotor muscles. In addition, it has been suggested that reductions in respiratory effort could lead to greater locomotor muscle recruitment mediated by central nervous system control (Edwards and

TABLE 2 | Evaluation of ventilatory efficiency variables in normoxia and hypoxia before the experimental period with data from both groups (Mean $\pm S D$ ).

\begin{tabular}{lcccc}
\hline & $\boldsymbol{V}_{\mathbf{E}} / \mathbf{V C O}_{\mathbf{2}}$ slope & $\mathbf{L E q C O}_{\mathbf{2}}$ & $\mathbf{E q C O}_{\mathbf{2}} \mathbf{V T} \mathbf{2}$ & OUES \\
\hline Normoxia $(n=16)$ & $24.58 \pm 2.95$ & $22.63 \pm 2.68$ & $23.91 \pm 2.34$ & $3.24 \pm 0.62$ \\
Hypoxia $(n=16)$ & $29.15 \pm 3.26^{\star}$ & $24.8 \pm 1.9^{\star}$ & $27.28 \pm 2.79^{\star}$ & $2.96 \pm 0.85^{\star}$ \\
$\% \Delta$ Change & $+18.5 \%$ & $+9.58 \%$ & $+14.09 \%$ & $-8.64 \%$
\end{tabular}

$\mathrm{V}_{E} \mathrm{NCO}_{2}$ slope, Slope of the relationship between $\mathrm{VCO}_{2}$ and $\mathrm{V}_{E} ; \mathrm{LEqCO}$, lowest equivalent of $\mathrm{CO}_{2}$ during the incremental test; $\mathrm{EqCO}_{2} V T_{2}$, equivalent of $\mathrm{CO}_{2}$ in the second ventilatory threshold; OUES, oxygen uptake efficiency slope; \% $\triangle$ Change, Percentage of change between measurements.

${ }^{*} t$-Test for paired samples $(p<0.05)$.
Walker, 2009). Once more, it should be noted that despite the improvements found in the IMTG no interaction effect was found. Thus, outcomes should be interpreted with some caution.

A further finding of the present investigation was that most of the ventilatory efficiency variables $\left(V_{\mathrm{E}} / \mathrm{VCO}_{2}\right.$ slope, $\mathrm{LEqCO}_{2}$ and $\mathrm{EqCO}_{2} \mathrm{VT}_{2}$ ) were not related to TT performance (Table 6; Figure 5). This is in contrast to the finding of Sheel (2002) who suggests that improvements in submaximal exercise performance after IMT are related to improvements in ventilatory efficiency. Nonetheless, results of the present investigation show a positive relationship between cycling time trial performance and respiratory muscle strength $\left(r^{2}=0.695\right.$; Figure 3). It could be argued that the increased respiratory muscle strength might reduce the oxygen cost of breathing during submaximal exercise, thus improving oxygen delivery to the working limb muscles. However, further studies are necessary to confirm this hypothesis. In contrast, OUES showed a linear relationship with cycling TT performance $\left(r^{2}=0.647\right.$; Figure 5). Subjects who showed a lower oxygen cost for the same increment in $V_{\mathrm{E}}$ are those who achieved a higher performance in the TT ( $\mathrm{W}_{\text {TTmean }}$; Table 6). However, OUES was not modified by the IMT (Table 3) and was not related to Pimax (Table 6). Therefore, IMT seems to not play a role in this relationship. It should be mentioned that in contrast to our trained sample, OUES was modified by IMT in patients with heart failure and weakened breathing muscle (Winkelmann et al., 2009).

Regarding the incremental exercise test, $\mathrm{VO}_{2 \max }$ in hypoxia was reduced in both groups (-8.99\% IMTG; $-11.92 \%$ CG). Similar reductions were found previously at this simulated altitude (Lawler et al., 1988; Martin and O’kroy, 1993). Additionally, IMT did not improve $\mathrm{VO}_{2 \max }$ in normoxia and hypoxia (Table 5). Our results support previous studies that did not find an effect of IMT on $\mathrm{VO}_{2 \max }$ in normoxia and hypoxia (Downey et al., 2007; Esposito et al., 2010). However, the IMTG improved PPO after IMT in normoxia $(+5.62 \%)$ and hypoxia

TABLE 3 | Comparison between groups in ventilatory efficiency variables in the four experimental conditions.

\begin{tabular}{|c|c|c|c|c|c|c|c|c|}
\hline \multirow[t]{2}{*}{ IMTG } & \multicolumn{2}{|r|}{ Pre } & \multicolumn{2}{|r|}{ Post } & \multicolumn{4}{|c|}{ ANOVA } \\
\hline & Normoxia & Hypoxia & Normoxia & Hypoxia & $\begin{array}{c}\text { Main effect } \\
\text { (time) }\end{array}$ & $\begin{array}{l}\text { Main effect } \\
\text { (condition) }\end{array}$ & $\begin{array}{c}\text { Main effect } \\
\text { (group) }\end{array}$ & $\begin{array}{c}\text { Interaction (condition } \mathrm{x} \\
\text { group } \mathrm{x} \text { time) }\end{array}$ \\
\hline$V_{\mathrm{E}} \mathrm{NCO}_{2}$ slope & $23.68 \pm 2.94$ & $28.77 \pm 2.74 \#(1.3)$ & $25.6 \pm 3.95$ & $26.48 \pm 2.77^{\star}(0.42)$ & 0.267 & 0.000 & 0.476 & 0.313 \\
\hline $\mathrm{LEqCO}_{2}$ & $22.51 \pm 1.32$ & $24.72 \pm 1.45 \#(1.2)$ & $22.73 \pm 1.65$ & 23.98 土 1.64\# (0.83) & 0.609 & 0.000 & 0.755 & 0.519 \\
\hline $\mathrm{EqCO}_{2} \mathrm{VT}_{2}$ & $23.68 \pm 2.33$ & $27.26 \pm 2.94 \#(1.3)$ & $24.32 \pm 2.92$ & $24.38 \pm 2.11^{*}(1.5)$ & 0.022 & 0.000 & 0.733 & 0.233 \\
\hline OUES & $3.22 \pm 0.75$ & $3.13 \pm 0.82$ & $3.31 \pm 0.83$ & $2.92 \pm 0.71 \#(0.81)$ & 0.493 & 0.007 & 0.994 & 0.203 \\
\hline \multicolumn{9}{|l|}{ CG } \\
\hline$V_{E} \mathrm{NCO}_{2}$ slope & $25.31 \pm 2.35$ & $29.81 \pm 3.7 \#(1.7)$ & $25.63 \pm 3.93$ & $28.06 \pm 3.5^{\star} \#\left(1.2^{\star}-1.3 \#\right)$ & - & - & - & - \\
\hline $\mathrm{LEqCO}_{2}$ & $22.75 \pm 3.59$ & $24.87 \pm 2.17 \#(0.5)$ & $22.62 \pm 1.98$ & $24.73 \pm 1.58 \#(1.9)$ & - & - & - & - \\
\hline $\mathrm{EqCO}_{2} \mathrm{VT}_{2}$ & $24.26 \pm 2.05$ & $27.15 \pm 2.81 \#(0.8)$ & $24.15 \pm 3.11$ & $25.7 \pm 2.73^{\star}(0.8)$ & - & - & - & - \\
\hline OUES & $3.36 \pm 0.56$ & $2.98 \pm 0.91$ & $3.24 \pm 0.52$ & $3.01 \pm 0.55 \#(1.0)$ & - & - & - & - \\
\hline
\end{tabular}

Data are presented as Mean $\pm S D$ and Effect size (ES). ES is showed when a statistical difference was found. $V_{E} / V_{C O}$ slope, Slope of the relationship between $V C O_{2}$ and $V_{E} ; L E q C O_{2}$,

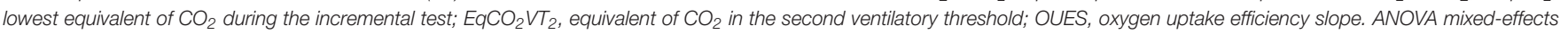
Bonferroni post-hoc test:

*Mixed-effects ANOVA Pre vs. Post in the same condition $(p<0.05)$.

\#Mixed-effects ANOVA Nor vs. Hyp at the same time $(p<0.05)$. 
TABLE 4 | Comparison between groups in time trial variables in the four experimental conditions.

\begin{tabular}{|c|c|c|c|c|c|c|c|c|}
\hline \multirow[t]{2}{*}{ IMTG } & \multicolumn{2}{|r|}{ Pre } & \multicolumn{2}{|r|}{ Post } & \multicolumn{4}{|c|}{ ANOVA } \\
\hline & Normoxia & Hypoxia & Normoxia & Hypoxia & $\begin{array}{c}\text { Main effec } \\
\text { (time) }\end{array}$ & $\begin{array}{l}\text { Main effect } \\
\text { (condition) }\end{array}$ & $\begin{array}{l}\text { Main effect } \\
\text { (group) }\end{array}$ & $\begin{array}{l}\text { Interaction } \\
\text { (condition } x \\
\text { group } \times \text { time) }\end{array}$ \\
\hline $\mathrm{W}_{\text {TTmean }}(\mathrm{W})$ & $217.25 \pm 49.07$ & $204.5 \pm 49.67 \#(1.0)$ & $241.87 \pm 56.01^{\star}(1.9)$ & $219 \pm 51.22 \# \#^{*}\left(0.6 \#-0.6^{*}\right)$ & 0.026 & 0.000 & 0.755 & 0.611 \\
\hline $\mathrm{W}_{\text {TTmean }}(\mathrm{W} / \mathrm{Kg})$ & $3.03 \pm 0.4$ & $2.83 \pm 0.45 \#(1.3)$ & $3.35 \pm 0.4^{\star}(2.4)$ & $3.07 \pm 0.44 \# \#^{*}\left(1.8 \#-1.5^{\star}\right)$ & 0.041 & 0.000 & 0.823 & 0.610 \\
\hline $\mathrm{W}_{\text {TTmax }}(\mathrm{W})$ & $296.25 \pm 109.6$ & $282.3 \pm 112$ & $319.12 \pm 118$ & $289 \pm 105.9 \#(1.8)$ & 0.969 & 0.000 & 0.353 & 0.769 \\
\hline PTF (W) & $147.5 \pm 22.83$ & $141.25 \pm 27.35$ & $156.87 \pm 29.51^{\star}(1.1)$ & $144.37 \pm 27.57 \#(2.3)$ & 0.466 & 0.000 & 0.676 & 0.164 \\
\hline \multicolumn{9}{|l|}{ CG } \\
\hline $\mathrm{W}_{T T \text { mean }}(\mathrm{W})$ & $221.25 \pm 32.5$ & 209.12 土 37.47\# (1.6) & $222 \pm 35.25$ & $202.62 \pm 36.23 \#(2.9)$ & - & - & - & - \\
\hline $\mathrm{W}_{\text {TTmean }}(\mathrm{W} / \mathrm{Kg})$ & $3.08 \pm 0.39$ & $2.88 \pm 0.43 \#(1.6)$ & $3.11 \pm 0.32$ & $2.89 \pm 0.32 \#(2.8)$ & - & - & - & - \\
\hline $\mathrm{W}_{\text {TTmax }}(\mathrm{W})$ & $273.28 \pm 28.87$ & $258.37 \pm 36.89$ & $265 \pm 39.84$ & $238.7 \pm 37.45 \#(2.6)$ & - & - & - & - \\
\hline PTF $(W)$ & $161.87 \pm 22.19$ & $146.87 \pm 21.86 \#(1.7)$ & $156.87 \pm 22.98$ & $144.75 \pm 21.59 \#(1.0)$ & - & - & - & - \\
\hline
\end{tabular}

Data are presented as Mean $\pm S D$ and Effect size (ES). ES is showed when a statistical difference was found. $W_{\text {TTmax }}$ Peak power output; $W_{\text {TTmean }}(W)$, mean watts; $W_{T T m e a n}(W / K g)$, mean watts per kilogram; PTF, pedal torque force. ANOVA mixed-effects Bonferroni post-hoc test.

*Mixed-effects ANOVA Pre vs. Post in the same condition $(p<0.05)$.

\#Mixed-effects ANOVA Nor vs. Hyp at the same time ( $p<0.05)$.

TABLE 5 | Measured cardiorespiratory and performance variables at maximal exercise intensity in the four experimental conditions.

\begin{tabular}{|c|c|c|c|c|c|c|c|c|}
\hline \multirow[t]{2}{*}{ IMTG } & \multicolumn{2}{|r|}{ Pre } & \multicolumn{2}{|c|}{ Post } & \multicolumn{4}{|c|}{ ANOVA } \\
\hline & Normoxia & Hypoxia & Normoxia & Hypoxia & $\begin{array}{c}\text { Main effec } \\
\text { (time) }\end{array}$ & $\begin{array}{l}\text { Main effect N } \\
\text { (condition) }\end{array}$ & $\begin{array}{l}\text { Main effect } \\
\text { (group) }\end{array}$ & $\begin{array}{l}\text { Interaction } \\
\text { (condition } x \\
\text { group } x \text { time) }\end{array}$ \\
\hline $\mathrm{VO}_{2 \max }\left(\mathrm{ml} \cdot \mathrm{kg} \cdot \mathrm{min}^{-1}\right)$ & $47.19 \pm 9.45$ & $45.15 \pm 7.34$ & $45.86 \pm 5.07$ & $43.37 \pm 6.88 \#(0.6)$ & 0.139 & 0.018 & 0.973 & 0.731 \\
\hline PPO (W) & $289.37 \pm 55.12$ & $274.62 \pm 53.28 \#(0.7)$ & $306.62 \pm 58.86^{*}(0.9)$ & $281.5 \pm 51.37 \#(2.0)$ & 0.180 & 0.000 & 0.778 & 0.660 \\
\hline$V_{\text {Emax }}\left(1 \cdot \min ^{-1}\right)$ & $141.12 \pm 32.24$ & $146.75 \pm 34.58$ & $150.37 \pm 28.99$ & $143.62 \pm 23.46$ & 0.785 & 0.525 & 0.919 & 0.105 \\
\hline $\mathrm{V}_{\text {Tmax }}(\mathrm{l})$ & $3.06 \pm 0.79$ & $3.07 \pm 0.72$ & $3.04 \pm 0.58$ & $3.03 \pm 0.65$ & 0.779 & 0.911 & 0.628 & 0.865 \\
\hline $\mathrm{BF}_{\max }\left(\right.$ breaths $\cdot \min ^{-1}$ ) & $57.25 \pm 5.54$ & $56.5 \pm 7.72$ & $57.12 \pm 5.93$ & $56 \pm 7.38$ & 0.468 & 0.711 & 0.488 & 0.850 \\
\hline \multicolumn{9}{|l|}{ CG } \\
\hline $\mathrm{VO}_{2 \max }\left(\mathrm{ml} \cdot \mathrm{kg} \cdot \mathrm{min}^{-1}\right)$ & $49 \pm 8.37$ & $43.78 \pm 7.24$ & $46.51 \pm 4.1$ & $42.67 \pm 4.06 \#(2.3)$ & - & - & - & - \\
\hline $\mathrm{PPO}(\mathrm{W})$ & $306.62 \pm 41.86$ & $285.5 \pm 43.1 \#(2.1)$ & $307.75 \pm 47.67$ & $280.25 \pm 44.65 \#(1.9)$ & - & - & - & - \\
\hline$V_{E \max }\left(1 \cdot \min ^{-1}\right)$ & $143.5 \pm 35.97$ & $148.5 \pm 42.57$ & $135.87 \pm 40.92$ & $147.12 \pm 43.6$ & - & - & - & - \\
\hline$V T_{\max }(I)$ & $2.87 \pm 0.75$ & $2.93 \pm 0.77$ & $2.88 \pm 0.8$ & $2.87 \pm 0.82$ & - & - & - & - \\
\hline $\mathrm{BF}_{\max }\left(\right.$ breaths $\left.\cdot \mathrm{min}^{-1}\right)$ & $59.25 \pm 10.87$ & $62 \pm 9.81$ & $57.75 \pm 14$ & $59.12 \pm 11.24$ & - & - & - & - \\
\hline
\end{tabular}

Data are presented as Mean $\pm S D$ and Effect size (ES). ES is showed when a statistical difference was found. VO 2 max, Maximum oxygen uptake; PPO, peak power output; $V_{\text {Emax }}$ maximum ventilation; $V T_{\text {max }}$, maximum tidal volume; $B F_{\text {max }}$, maximum breathing frequency. ANOVA mixed-effects Bonferroni post hoc test:

*Mixed-effects ANOVA Pre vs. Post in the same condition $(p<0.05)$.

\#Mixed-effects ANOVA Nor vs. Hyp at the same time $(p<0.05)$.

$(+2.51 \%)$ which is in contrast to previous studies that reported only a slight influence of IMT on PPO (Sheel, 2002; Illi et al., 2012). Moreover, except for OUES, the ventilatory efficiency variables were not correlated with performance variables of the incremental test (Table 6). Similar to the time trial outcome, OUES showed a strong correlation with $\mathrm{VO}_{2 \max }$ in normoxia and hypoxia ( $r=0.89$ and $r=0.82$; respectively) and with PPO $(r=$ 0.91 and $r=0.88$; respectively). With respect to this finding, there are contrasting results reported in the literature. There are studies reporting a correlation between $\mathrm{VO}_{2 \max }$ and OUES (Baba et al., 1999a,b,c; Hollenberg and Tager, 2000) and others that did not find a correlation between these two parameters or only a weak correlation (Brown, 2010; Brown et al., 2013). Further research is necessary on the influence of IMT on ventilatory efficiency parameters in hypoxia.

Some limitations have to be addressed. First, the sample size was large enough to detect changes in Pimax and performance within the intervention group but might have been too low to detect group differences. Second, we do not have exact data on the amount of training and competitions completed by the subjects apart from the inspiratory training load. However, participants were advised not to change their usual training habits during the experimental period. All participants were enrolled in the same practical courses, and all reported to only 
TABLE 6 | Correlation analysis between performance variables and ventilatory efficiency variables after experimental protocol with data from both groups.

\begin{tabular}{ccccc}
\multicolumn{5}{c}{ Pearson-r } \\
\hline $\begin{array}{c}\mathrm{W}_{\mathrm{TTmean}} \\
\text { (W) }\end{array}$ & $\mathrm{VO}_{2 \max }$ & $\mathrm{V}_{\mathrm{Emax}}$ & $\mathrm{Pi}_{\max }$ & $\mathrm{PPO}$ \\
$\left(\mathrm{ml} \cdot \mathrm{kg} \cdot \mathrm{min}^{-1}\right)$ & $\left(1 \cdot \mathrm{min}^{-1}\right)$ & $\left(\mathrm{cmH}_{2} \mathrm{O}\right)$ & (W)
\end{tabular}

\begin{tabular}{|c|c|c|c|c|c|}
\hline \multicolumn{6}{|l|}{ NORMOXIA } \\
\hline $\operatorname{Pimax}_{\left(\mathrm{cmH}_{2} \mathrm{O}\right)}$ & $0.607^{*}$ & $0.503^{\star}$ & $0.859^{*}$ & 1 & $0.623^{*}$ \\
\hline$V_{E} N_{C O}$ slope & 0.126 & 0.153 & 0.278 & 0.361 & 0.036 \\
\hline $\mathrm{LEqCO}_{2}$ & 0.011 & 0.083 & 0.288 & 0.274 & -0.064 \\
\hline $\mathrm{EqCO}_{2} \mathrm{VT}_{2}$ & -0.1 & 0.026 & 0.062 & 0.196 & -0.220 \\
\hline OUES & $0.89^{*}$ & $0.683^{*}$ & $0.669^{*}$ & 0.454 & $0.913^{*}$ \\
\hline \multicolumn{6}{|l|}{ HYPOXIA } \\
\hline $\operatorname{Pimax}\left(\mathrm{cmH}_{2} \mathrm{O}\right)$ & $0.599^{*}$ & 0.477 & $0.545^{\star}$ & 1 & $0.587^{*}$ \\
\hline$V_{E} / \mathrm{NCO}_{2}$ slope & 0.060 & 0.045 & 0.145 & 0.304 & 0.029 \\
\hline $\mathrm{LEqCO}_{2}$ & -0.250 & -0.084 & -0.029 & 0.069 & -0.283 \\
\hline $\mathrm{EqCO}_{2} \mathrm{VT}_{2}$ & -0.105 & -0.016 & -0.019 & 0.131 & -0.166 \\
\hline OUES & $0.828^{*}$ & $0.664^{*}$ & $0.79^{\star}$ & 0.408 & $0.885^{\star}$ \\
\hline
\end{tabular}

Pimax, Peak inspiratory pressure; $V_{E} \mathrm{NCO}_{2}$ slope, Slope of the relationship between $V \mathrm{CO}_{2}$ and $V_{E} ; L E q C \mathrm{CO}_{2}$, lowest equivalent of $\mathrm{CO}_{2}$ during the incremental test; $E q \mathrm{CO}_{2} V T_{2}$, equivalent of $\mathrm{CO}_{2}$ in the second ventilatory threshold; OUES, oxygen uptake efficiency slope; $\mathrm{VO}_{2 \max }$, Maximum oxygen uptake; PPO, peak power output; VEmax, maximum ventilation; WTTmean, mean watts

*Significant correlation $(p<0.05)$.

have limited time for sports outside of the university setting. In addition, it was reported that conventional training (no specific breathing training) does not improve breathing muscle strength (Illi et al., 2012). Therefore, we can assume that they completed approximately the same training apart from the IMT and this did not influence our results. Third, we did not measure the oxygen saturation $\left(\mathrm{SaO}_{2}\right)$ during the hypoxia trials and this may have contributed important information. Lastly, we did not control for a possible placebo effect. However, as it is stated in the methods section, a large placebo effect is not expected. Therefore, we are confident that our conclusions were not affected.

\section{REFERENCES}

Arena, R., Myers, J., and Guazzi, M. (2008). The clinical and research applications of aerobic capacity and ventilatory efficiency in heart failure: an evidence-based review. Heart Fail. Rev. 13, 245-269. doi: 10.1007/s10741-0079067-5

Baba, R., Kubo, N., Morotome, Y., and Iwagaki, S. (1999a). Reproducibility of the oxygen uptake efficiency slope in normal healthy subjects. J. Sports Med. Phys. Fitness 39, 202-206.

Baba, R., Nagashima, M., Goto, M., Nagano, Y., Yokota, M., Tauchi, N., et al. (1996). Oxygen intake efficiency slope: a new index of cardiorespiratory functional reserve derived from the relationship between oxygen consumption and minute ventilation during incremental exercise. J. Am. Coll. Cardiol. 59, 55-62.

Baba, R., Nagashima, M., Nagano, Y., Ikoma, M., and Nishibata, K. (1999b). Role of the oxygen uptake efficiency slope in evaluating exercise tolerance. Arch. Dis. Child. 81, 73-75. doi: 10.1136/adc.81.1.73

Baba, R., Tsuyuki, K., Kimura, Y., Ninomiya, K., Aihara, M., Ebine, K., et al. (1999c). Oxygen uptake efficiency slope as a useful measure of cardiorespiratory

\section{CONCLUSIONS}

Even though sample size might have been too low to show an interaction effect, the results of the present study suggest a possible positive effect of IMT on cycling time trial performance in both normoxic and hypoxic conditions. Additionally, this study shows that hypoxia has a negative effect on the ventilatory efficiency and that IMT may reduce this effect. Finally, the data suggest that except or OUES, ventilatory efficiency measures seem not to affect cycling time trial performance. These findings may have relevance for athletes planning to complete a high altitude training camp or for athletes competing at high altitude. IMT before a competition at altitude might be a successful method to improve performance.

\section{ETHICS STATEMENT}

This study was carried out in accordance with the recommendations of Ethics Committee of the University of Innsbruck with written informed consent from all subjects. All subjects gave written informed consent in accordance with the Declaration of Helsinki. The protocol was approved by the Ethics Committee of the University of Innsbruck.

\section{AUTHOR CONTRIBUTIONS}

Conception and design of the experiments: ES, AS, and JNO; Pretesting, experimental preparation, data collection, and analysis: ES and HG. The first version of the manuscript was written by ES, HG, MB, JNO, and AS. All co-authors read and approved the final version of the manuscript.

\section{ACKNOWLEDGMENTS}

The investigators would like to thank the sport students whose cooperation made this study possible and the researcher Antonio Pérez for his assistance.

functional reserve in adult cardiac patients. Eur. J. Appl. Physiol. Occup. Physiol. 80, 397-401. doi: 10.1007/s004210050610

Babcock, M. A., Johnson, B. D., Pegelow, D. F., Suman, O. E., Griffin, D., and Dempsey, J. A. (1995). Hypoxic effects on exercise-induced diaphragmatic fatigue in normal healthy humans. J. Appl. Physiol. 78, 82-92.

Bernardi, L., Schneider, A., Pomidori, L., Paolucci, E., and Cogo, A. (2006). Hypoxic ventilatory response in successful extreme altitude climbers. Eur. Respir. J. 27, 165-171. doi: 10.1183/09031936.06.00015805

Brown, S. J. (2010). Cardio-respiratory system efficiency in trained endurance cyclists. Med. Sportiva 14, 176-181. doi: 10.2478/v10036-010-0028-z

Brown, S. J., Raman, A., Schlader, Z., and Stannard, S. R. (2013). Ventilatory efficiency in juvenile elite cyclists. J. Sci. Med. Sport 16, 266-270. doi: 10.1016/j.jsams.2012.06.010

Burtscher, M., Faulhaber, M., Flatz, M., Likar, R., and Nachbauer, W. (2006). Effects of short-term acclimatization to altitude $(3200 \mathrm{~m})$ on aerobic and anaerobic exercise performance. Int. J. Sports Med. 27, 629-635. doi: $10.1055 / \mathrm{s}-2005-872823$

Dempsey, J. A., and Forster, H. V. (1982). Mediation of ventilatory adaptations. Physiol. Rev. 62, 262-346. 
Downey, A. E., Chenoweth, L. M., Townsend, D. K., Ranum, J. D., Ferguson, C. S., and Harms, C. A. (2007). Effects of inspiratory muscle training on exercise responses in normoxia and hypoxia. Respir. Physiol. Neurobiol. 156, 137-146. doi: 10.1016/j.resp.2006.08.006

Edwards, A. M., and Walker, R. E. (2009). Inspiratory muscle training and endurance: a central metabolic control perspective. Int. J. Sports Physiol. Perform. 4, 122-128. doi: 10.1123/ijspp.4.1.122

Esposito, F., Limonta, E., Alberti, G., Veicsteinas, A., and Ferretti, G. (2010). Effect of respiratory muscle training on maximum power in normoxia and hypoxia. Respir. Physiol. Neurobiol. 170, 268-272. doi: 10.1016/j.resp.2010.02.004

Faiss, R., Von Orelli, C., Deriaz, O., and Millet, G. P. (2014). Responses to exercise in normobaric hypoxia: comparison of elite and recreational ski mountaineers. Int. J. Sports Physiol. Perform. 9, 978-984. doi: 10.1123/ijspp.2013-0524

Harms, C. A., Babcock, M. A., McClaran, S. R., Pegelow, D. F., Nickele, G. A., Nelson, W. B., et al. (1997). Respiratory muscle work compromises leg blood flow during maximal exercise. J. Appl. Physiol. 82, 1573-1583.

Hollenberg, M., and Tager, I. B. (2000). Oxygen uptake efficiency slope: an index of exercise performance and cardiopulmonary reserve requiring only submaximal exercise. J. Am. Coll. Cardiol. 36, 194-201. doi: 10.1016/S0735-1097(00)00691-4

Howley, E. T., Bassett, D. R., and Welch, H. G. (1995). Criteria for maximal oxygen uptake: review and commentary. Med. Sci. Sports Exerc. 27, 1292-1301. doi: 10.1249/00005768-199509000-00009

Illi, S. K., Held, U., Frank, I., and Spengler, C. M. (2012). Effect of respiratory muscle training on exercise performance in healthy individuals. Sports Med. 42, 707-724. doi: 10.1007/BF03262290

Ingle, L., Goode, K., Carroll, S., Sloan, R., Boyes, C., Cleland, J. G. F., et al. (2007). Prognostic value of the $\mathrm{V}_{\mathrm{E}} / \mathrm{VCO}_{2}$ slope calculated from different time intervals in patients with suspected heart failure. Int. J. Cardiol. 118, 350-355. doi: 10.1016/j.ijcard.2006.07.105

Laveneziana, P., Agostoni, P., Mignatti, A., Mushtaq, S., Colombo, P., Sims, D., et al. (2010). Effect of acute $\beta$-blocker withholding on ventilatory efficiency in patients with advanced chronic heart failure. J. Card. Fail. 16, 548-555. doi: 10.1016/j.cardfail.2010.02.006

Lawler, J., Powers, S. K., and Thompson, D. (1988). Linear relationship between $\mathrm{VO}_{2 \max }$ and $\mathrm{VO}_{2 \max }$ decrement during exposure to acute hypoxia. J. Appl. Physiol. 64, 1486-1492.

Lucía, A., Hoyos, J., Pérez, M., and Chicharro, J. L. (2000). Heart rate and performance parameters in elite cyclists: a longitudinal study. Med. Sci. Sports Exerc. 32, 1777-1782. doi: 10.1097/00005768-200010000-00018

Magrì, D., Limongelli, G., Re, F., Agostoni, P., Zachara, E., Correale, M., et al. (2016). Cardiopulmonary exercise test and sudden cardiac death risk in hypertrophic cardiomyopathy. Heart 102, 602-609. doi: 10.1136/heartjnl2015-308453

Martin, D., and O'kroy, J. (1993). Effects of acute hypoxia on the VO2 max of trained and untrained subjects. J. Sports Sci. 11, 37-42. doi: 10.1080/02640419308729961

Mourot, L., Perrey, S., Tordi, N., and Rouillon, J. D. (2004). Evaluation of fitness level by the oxygen uptake efficiency slope after a short-term intermittent endurance training. Int. J. Sports Med. 25, 85-91. doi: 10.1055/s-2004-819943

Ozcelik, O., and Kelestimur, H. (2004). Effects of acute hypoxia on the estimation of lactate threshold from ventilatory gas exchange indices during an incremental exercise test. Physiol. Res. 53, 653-659.
Romer, L. M., McConnell, A. K., and Jones, D. A. (2002a). Effects of inspiratory muscle training on time-trial performance in trained cyclists. J. Sports Sci. 20, 547-590. doi: 10.1080/026404102760000053

Romer, L. M., McConnell, A. K., and Jones, D. A. (2002b). Inspiratory muscle fatigue in trained cyclists: effects of inspiratory muscle training. Med. Sci. Sports Exerc. 34, 785-792. doi: 10.1097/00005768-20020500000010

Roussos, C. (1985). Function and fatigue of respiratory muscles. Chest 88, 124S-132S. doi: 10.1378/chest.88.2_Supplement.124S

Rusko, H., Tikkanen, H., and Peltonen, J. (2004). Altitude and endurance training. J. Sports Sci. 22, 928-945. doi: 10.1080/02640410400005933

Salazar-Martínez, E., Terrados, N., Burtscher, M., Santalla, A., and Orellana, J. N. (2016). Ventilatory efficiency and breathing pattern in world-class cyclists: a three-year observational study. Respir. Physiol. Neurobiol. 229, 17-23. doi: 10.1016/j.resp.2016.04.001

Sheel, A. W. (2002). Respiratory muscle training in healthy individuals. Sports Med. 32, 567-581. doi: 10.2165/00007256-200232090-00003

Sun, X.-G., Hansen, J. E., Garatachea, N., Storer, T. W., and Wasserman, K. (2002). Ventilatory efficiency during exercise in healthy subjects. Am. J. Respir. Crit. Care Med. 166, 1443-1448. doi: 10.1164/rccm.2202033

Townsend, N. E., Gore, C. J., Hahn, A. G., McKenna, M. J., Aughey, R. J., Clark, S. A., et al. (2002). Living high-training low increases hypoxic ventilatory response of well-trained endurance athletes. J. Appl. Physiol. 93, 1498-1505. doi: 10.1152/japplphysiol.00381.2002

Volianitis, S., McConnell, A. K., Koutedakis, Y., McNaughton, L. R., Backx, K., and Jones, D. A. (2001). Inspiratory muscle training improves rowing performance. Med. Sci. Sports Exerc. 33, 803-809. doi: 10.1097/00005768-20010500000020

Warner, M. M., and Mitchell, G. S. (1990). Ventilatory responses to hyperkalemia and exercise in normoxic and hypoxic goats. Respir. Physiol. 82, 239-249. doi: 10.1016/0034-5687(90)90038-Z

Wells, G. D., Plyley, M., Thomas, S., Goodman, L., and Duffin, J. (2005). Effects of concurrent inspiratory and expiratory muscle training on respiratory and exercise performance in competitive swimmers. Eur. J. Appl. Physiol. 94, 527-540. doi: 10.1007/s00421-005-1375-7

Winkelmann, E. R., Chiappa, G. R., Lima, C. O. C., Viecili, P. R. N., Stein, R., and Ribeiro, J. P. (2009). Addition of inspiratory muscle training to aerobic training improves cardiorespiratory responses to exercise in patients with heart failure and inspiratory muscle weakness. Am. Heart 158, 768.e1-e7. doi: 10.1016/j.ahj.2009.09.005

Conflict of Interest Statement: The authors declare that the research was conducted in the absence of any commercial or financial relationships that could be construed as a potential conflict of interest.

Copyright (c) 2017 Salazar-Martínez, Gatterer, Burtscher, Naranjo Orellana and Santalla. This is an open-access article distributed under the terms of the Creative Commons Attribution License (CC BY). The use, distribution or reproduction in other forums is permitted, provided the original author(s) or licensor are credited and that the original publication in this journal is cited, in accordance with accepted academic practice. No use, distribution or reproduction is permitted which does not comply with these terms. 